\title{
The use of a hydrological model in water resources planning
}

\author{
R. E. MANLEY
}

Dr J. K. White, University of London, King's College

The Author's model is remarkable in that it achieves such an accurate simulation of flows for a catchment as complex as the Severn. I believe that this success is due primarily to the philosophy of basing the model on physically identifiable parameters, and represents a triumph for engineering science over blind systems analysis.

68. In my view the outstanding problem in developing a model of this sort is the identification of suitable representations of the interface or vertical leakage flows. Two interface flows in particular-the loss from precipitation by evaporation and evapotranspiration, and the loss to long-term groundwater storage-are used by the Author to obtain a water balance. In a catchment model study of the Plynlimon catchments of the Wye and Severn I found that the stream flow mean in storm data could be anywhere between $5 \%$ and $65 \%$ of the rainfall mean, and $I$ had to make rather crude adjustments to the rainfall record in order to obtain continuity. I felt that the severity of this adjustment rather overshadowed the accuracy of fit that I was able to achieve by subsequent optimization, and it made me wary of the values of the physical parameters that were obtained. To what extent did the Author have to adjust rainfall data or lose water to long-term storage in order to obtain a water balance? Does he think this can be done in a sufficiently consistent manner to be confident that the simulation of storms -which may be of particular significance in the design of a water resource scheme-is being achieved accurately?

69. What are the units of the parameters given in Table 2 and how are these parameters related to the parameter notation in the text? Also in Table 2, is the reduced error of estimate a percentage or a fraction?

\section{Mr Manley}

In the modelling of the Severn there was no justification for assuming that water was lost by groundwater leakage; consequently none was allowed for. A water balance was achieved by applying a factor to the potential evapotranspiration estimates, the figures used being $0.78,0.80$ and 0.98 for the Teme, Avon and Stour respectively. I believe this approach is preferable to adjusting the rainfall figures, because rainfall is usually more adequately measured, and is justified by the difference between the effective degree of exposure of the catchment and of the meteorological measuring site.

71. Table 4 (shown overleaf) gives the units of the parameters and the symbols used in the Paper. The reduced error of estimate is a fraction. 
Table 4

\begin{tabular}{|c|c|c|}
\hline Parameter & Unit & $\begin{array}{l}\text { Symbol } \\
\text { (if used) }\end{array}$ \\
\hline $\begin{array}{c}\text { Interception storage } \\
\text { Minor channel coefficient } \\
\text { Total storage: upper horizon } \\
\text { lower horizon } \\
\text { Permeability: top of upper horizon } \\
\text { horizon boundary } \\
\text { base of lower horizon } \\
\text { Residual saturation } \\
\text { Bubbling pressure } \\
\text { Interflow run-off: upper horizon } \\
\text { lower horizon } \\
\text { Discharge coefficient : groundwater } \\
\text { transitional } \\
\text { groundwater }\end{array}$ & $\begin{array}{l}\mathrm{mm} \\
\mathrm{mm}^{-0} \cdot 5 / \mathrm{h} \\
\mathrm{mm} \\
\mathrm{mm} \\
\mathrm{mm} / \mathrm{h} \\
\mathrm{mm} / \mathrm{h} \\
\mathrm{mm} / \mathrm{h} \\
\mathrm{mm} \mathrm{of} \mathrm{water} \\
\mathrm{mm} / \mathrm{h} \\
\mathrm{mm} / \mathrm{h} \\
\text { proportion } / \mathrm{h} \\
\text { proportion } / \mathrm{h}\end{array}$ & $\begin{array}{l}k_{\mathrm{s} 1} \\
k_{\mathrm{s} 12} \\
k_{\mathrm{s} 2} \\
S_{\mathrm{r}} \\
P_{\mathrm{b}} \\
I S_{1} \\
I S_{2} \\
\\
D C_{\mathrm{Lg} \mathrm{w}}\end{array}$ \\
\hline
\end{tabular}

